\title{
The Use of Audiovisual Media as an Introduction to Local Culture for Foreign Students Participating in Indonesian Language Learning
}

\author{
Novia Rahmah Bastian ${ }^{1}$, Andayani ${ }^{2}$, Suyitno ${ }^{3}$ \\ ${ }^{123}$ Sebelas Maret University, Indonesia, \\ 1noviarahmahbastian@student.uns.ac.id
}

\begin{abstract}
Learning a language is a step towards mastering "a language". The success "of the language" learning step is influenced by two important elements, namely teacher and learner. Similarly, Indonesian language learning for Foreign Languages (BIPA) requires students to master both language and literature skills. Especially for middle school BIPA students. The learning process "is said to be successful if the" competencies taught by the teacher or teacher can be well mastered by the learner. There is a need for preparation by the teacher before passing on the competency to the student. Especially for BIPA students, the literature must be quite foreign to them even though few are familiar with the literature in their respective countries. Therefore, BIPA educators should use a variety of innovative learning tricks, one of them by applying learning media according to the competencies that BIPA learners will teach. Learning and knowing Indonesian culture is a great way to teach using audiovisual media in the form of video. Video media is a medium that displays images, gestures, and sounds that will make the learning process for BIPA students more enjoyable and easier, while introducing the cultural diversity that Indonesia has to BIPA learners.
\end{abstract}

Keywords: Indonesian, BIPA, audiovisual media

\section{PENDAHULUAN}

Bahasa Indonesia mrupakan saatu dari bahasa di dunia yang mengalami kemajuan cukup signifikan. Fakta ini dapat dibuktikan dari banyaknya negara yang sudah mempelajari bahasa Indonesia yang hingga saat ini jumlahnya mencapai hingga lebih dari empat puluh lima negara di dunia. Hal ini membuat terjadinya kenaikan yang cukup signifikan salah satunya terdapat peningkatan jumlah lembaga pendidikan tinggi maupun lembaga pengajaran yang menyediakan layanan kursus untuk Bahasa Indonesia bagi Penutur Asing (BIPA).

Pemelajar asing yang ingin memahami bahasa Indonesia biasanya mempelajari tentang ragam formal yang biasa digunakan di bahasa Indonesia. Hal itu terjadi karena pengajar bahasa Indonesia umumnya tidak menerangkan bahasa percakapan sehari-hari [1]. Sarumpaet mengatakan "hal tersebut diperparah dengan sebuah kondisi lebih baik siswa asing membuat kesalahan dalam berbahasa yang benar dan formal daripada menggunakan ragam bahasa yang tidak baku dan salah"yang menjadi acuan pengajar bahasa Indonesia." 
"Ketiadaan pengajaran ragam nonformal bahasa Indonesia, berpotensi membuat para penutur asing yang mempelajari bahasa Indonesia mengalami gegar linguistik ketika mereka berusaha untuk bercakap-cakap secara informal dengan masyarakat pengguna bahasa Indonesia."

"BIPA merupakan akronim dari Bahasa Indonesia bagi Penutur Asing. Arti dari Bahasa Indonesia merupakan bahasa resmi dari negara Indonesia. Bahasa ini sudah banyak mengalami perkembangan dan kemudian digunakan sebagai alat komunikasi oleh Penutur Indonesia sendiri (BIPI) maupun oleh Penutur Asing (BIPA) [2]. Untuk dapat berkomunikasi dengan baik, BIPA harus mengalami proses belajar yang intensif. Universitas Negeri Semarang (UNNES) melalui bagian Unit Lembaga Pengembangan Pendidikan dan Profesi (LP3) yang telah mengembangkan Program BIPA.

Mahasiswa pemelajar program BIPA adalah mahasiswa-mahasiswa asing yang"mempunyai latar belakang bahasa dan budaya yang berbeda dengan negara Indonesia. Ketidaksamaan antara budaya dan bahasanya pun"memiliki konsekuensi dalam pemilihan materi bahasa Indonesia yang diajarkan pada mahasiswa asing, dikarena pemerolehan bahasa yang kedua, dipengaruhi secara kuat oleh bahasa asli dari mahasiswa tersebut [3]. Kusmiatun juga mendefinisikan pemelajar"BIPA, adalah orang yang belum bisa berbahasa Indonesia"atau bahkan belum pernah berbahasa Indonesia sebagai sarana komunikasinya, meskipun tidak menutup kemungkinan bahwa ia sudah bisa menguasai bahasa asing dari negara lainnya selain bahasa Indonesia. Kemampuan mempelajari BIPA itu berbeda-beda, mulai pemelajar tingkat pemula, tingkat menengah hingga pemelajar tingkat lanjut. Hal inilah yang membedakan sehingga timbul berbagai macam materi BIPA [4]. Suyitno juga melanjutkan bahwa pada materi-materi BIPA tercatat ada penulis, baik penulis asli Indonesia maupun asing yang berkontribusi dalam penulisan materi tersebut."Tujuan yang hendak dicapai ialah mempermudah pelajar memahami bahasa Indonesia dalam pembelajaranya, "meskipun dalam kenyataannya ditemukan banyak variasi dalam hal pendekatan, "teknik pengajaran, bahan ajar, maupun urutannya yang masingmasing penulis mengira bahwa buku yang ia susun merupakan buku yang"paling efektif untuk pelajaran bahasa Indonesia bagi mahasiswa asing"[5].

Pentingnya media pembelajaran yang disampaikan oleh Dale ada sebelas tingkatan berdasarkan tingkat kekonkretan hingga paling abstrak yakni"pemahaman langsung, pengalaman melalui benda tiruan, pengalaman melalui drama, demonstrasi, karyawisata, televisi, film, radio, visual, lambang visual, dan verbal"[6]. "Pengetahuan dapat diperoleh melalui pengalaman langsung dan pengalaman tidak langsung. Semakin langsung objek yang dipelajari, maka semakin konkret pengetahuan diperoleh; semakin tidak langsung pengetahuan itu diperoleh, maka semakin abstrak pengetahuan siswa. "

"Untuk dapat menghasilkan"pemelajar"bahasa Indonesia yang dapat memahami konteks kultural dan"linguistik, penulis menganggap bahwa"pembelajaran"bahasa harus didukung"dengan materi dan metode yang"sesuai. Sejauh ini"materi BIPA"yang ada masih bersifat konvensional dan"masih sedikit"materi BIPA yang menggabungkan antara materi"audiovisual dan"muatan lokal secara komprehensif. "Dalam konteks penggunaan"multimedia dan pembelajaran bahasa asing berbasis budaya, "pembelajaran BIPA masih jauh tertinggal dibandingkan dengan pembelajaran bahasa Inggris. "Penggunaan multimedia merupakan sebuah hal yang sangat mendesak mengingat kemajuan teknologi informasi saat ini."Di samping itu, penggunaan multimedia juga akan mempermudah pembelajar dalam mempelajari berbagai pengalaman kebahasaan dan kultur bahasa Indonesia."

Oleh karena itu, penulis berpendapat bahwa pembelajaran BIPA perlu menggunakan gabungan antara sentuhan multimedia dan konten budaya lokal. Penelitian-penelitian sebelumnya lebih menekankan kepada aspek [7], [8], [9] sedangkan penelitian-penelitian lain 
menerapkan [10], [11]. Berdasarkan uraian di atas penelitian ini bertujuan untuk bisa melengkapi penelitian-penelitian sebelumnya dan berfokus pada penggunaan media audiovisual sebagai pengantar budaya lokal bagi siswa asing yang berpartisipasi dalam pembelajaran Bahasa Indonesia.

"Berdasarkan pemaparan yang telah penulis jabarkan, penelitian ini dilakukan untuk mendeskripsikan dan menjelaskan bahwa pemakaian media audiovisual merupakan media yang tepat sebagai pengenalan budaya lokal Indonesia bagi mahasiswa Asing yang belajar di Indonesia yang biasa disebut dengan Mahasiswa BIPA. Materi BIPA yang telah diberikan diharapkan mampu menjadi alternatif materi BIPA yang mengakomodasi kebutuhan bagi pemelajar untuk mengetahui bahasa serta budaya Indonesia yang bersifat aplikatif.

\section{METODE PENELITIAN}

Penelitian ini merupakan penelitian deskriptif kualitatif dengan menggunakan strategi studi kasus."Adapun metode penelitian yang akan dilakukan menggunakan teknik wawancara observasi. Bentuk data dari penelitian ini berupa hasil wawancara, observasi, serta dokumen. Sumber data pada penelitian ini diperoleh dari mahasiswa BIPA tingkat menengah yang telah lulus dan mampu mengidentifikasi berbagai macam budaya Indonesia sebagai salah satu"kemampuan yang dimilikinya. Tak hanya itu, penulis juga menggunakan studi pustaka sebagai sumber"data pada penelitian ini." "Uji validitas yang dilakukan dengan menggunakan triangulasi metode"[12]. Bentuk data berupa hasil wawancara, observasi, dan dokumen dibandingkan dengan temuan yang pernah diteliti sebelumnya. Selanjutnya, teknik analisis data yang akan dilakukan mengacu pada teori [13] mengenai kualitatif interaktif. Peneliti melakukan wawancara secara mendalam dengan informan. Peneliti terlibat secara interaktif dengan informan sehingga menemukan beberapa pengetahuan yang baru. Berdasar pada temuan baru tersebut, peneliti dapat menyajikan dan menyimpulkannya.

\section{HASIL DAN PEMBAHASAN}

Mahasiswa asing pemelajar bahasa Indonesia berasal dari berbagai belahan negara di dunia, mereka juga memiliki bekal bahasa dan budaya dari daerahnya sendiri. Selain itu mereka juga memiliki perbedaan ragam bahasa dan kebudayaan yang mana tentunya sangat jauh berbeda dengan keanekaragaman bahasa dan budaya yang akan ia pelajari di Indonesia. Hal ini juga berpengaruh pada penggunaan"materi bahasa Indonesia yang akan diajarkan kepada mahasiswa asing pemelajar bahasa Indonesia."Penggunaan materi yang kurang sesuai dapat berpengaruh pada terjadinya kesulitan dan kebosanan dari pemelajar asing dalam menempuh studinya [5]. Tujuan mahasiswa pemelajar bahasa Indonesia (BIPA) salah satunya yakni mereka ingin lancar"dalam berbicara bahasa Indonesia serta dapat mengenal budaya Indonesia secara lebih dekat. Kelancaran dalam hal berbahasa Indonesia diperlukan bagi mahasiswa pemelajar BIPA dikarena mereka telah mempertimbangkan berbagai tujuan yakni pertama, mengambil program tentang Indonesia di universitas ia berasal, kedua, mereka akan melakukan penelitian di Indonesia, ketiga, mereka akan bekerja di Indonesia, keempat, mereka akan meneliti masalah bahasa Indonesia, dan terakhir mereka akan tinggal di Indonesia dalam waktu yang lama. Gambaran singkat tentang tujuan belajar BIPA tersebut ialah berimplikasi dalam penyiapan materi belajar yang sesuai dengan tujuan tersebut. Dengan demikian, penelitian ini berkaitan erat dengan masalah pemenuhan kebutuhan pemelajar mahasiswa asing."

Mahasiswa BIPA tingkat menengah dituntut untuk bisa memberikan hasil pengamatan atas peristiwa yang telah ia alami dan mampu mengungkapkan gagasan dari apa yang telah ia 
kerjakan sesuai dengan keahliannya, baik secara konkret maupun abstrak, dengan cukup lancar tanpa adanya halangan yang mengganggu mitra tutur. Hal ini merupakan salah satu poin capaian yang tertuang dalam Permendikbud RI Nomor 27 tahun 2007. Hasil penelitian ini menunjukkan bahwa peserta pemelajar BIPA tingkat menengah memiliki kesulitan untuk menguasai dan memahami budaya Indonesia termasuk dalam memaknai sebuah ujaran.

Berlandaskan pada pemerolehan hasil belajar yang sudah dirancang dalam pengajaran BIPA, langkah yang dipilih adalah langkah komunikatif, yang menegaskan bahwa hal tersebut adalah hakikat bahasa dan belajar bahasa. Hal tersebut sesuai dengan pendapat [7] yang menjelaskan bahwa asumsi langkah komunikatif mengenai hakikat bahasa adalah bahasa merupakan sistem dalam pengungkapan makna, sebagai alat bagi manusia untuk berkomunikasi serta berinteraksi, struktur bahasa mencerminkan fungsi penggunaannya dan fungsi komunikatifnya, serta unit utama bahasa bukan hanya berupa gramatikal saja melainkan fungsi dan makna komunikasi."

Berdasarkan hasil observasi serta wawancara, ternyata peserta didik yang datang untuk belajar di Indonesia salah satunya adalah bertujuan untuk bisa mengenal lebih jauh tentang Indonesia. Dari pernyataan tersebut ditemukan permasalahan seperti (1) Rendahnya pemahaman penggunaan kata yang dimiliki peserta didik. Meskipun sudah lumayan cukup lama berada di Indonesia ternyata tidak menutup kemungkinan bahwa mahasiswa asing juga mengalami kesulitan dalam mencerna sebuah kalimat. Seringnya ketidaktahuan mereka dalam mengungkapkan ujaran maka mereka mengungkapkannya dengan bahasa isyarat. (2) Kurangnya media pembelajaran sebagai panduan belajar peserta didik dalam pembelajaran BIPA. (3) peserta didik juga harus mengenal kebudayaan yang ada di Indonesia.

"Di dalam suatu pembelajaran bahasa, hal yang juga penting yakni media."Media pembelajaran dapat diklasifikasikan menjadi 3 (tiga) bagian, yaitu (a) Dilihat dari sifat media terbagi menjadi 3 (tiga) yaitu media auditif merupakan media yang dapat didengar saja, media visual, media ini hanya dapat dilihat tanpa mengandung unsur suara, dan media audiovisual, jenis media ini selain mengandung unsur suara juga mengandung unsur gambar yang dapat dilihat (b) dilihat dari kemampuan jangkauannya, media dapat pula dibagi ke dalam media yang memiliki daya liput yang luas dan serentak seperti radio dan televisi, dan media yang mempunyai daya liput yang terbatas oleh ruang dan waktu (c) Dilihat dari cara dan teknik pemakaiannya media dibagi menjadi 2 (dua) bagian yakni media yang diproyeksikan contohnya seperti film, slide dan sebagainya yang memerlukan alat proyeksi khusus seperti dalam film proyektor, dan media yang tidak diproyeksikan contohnya seperti gambar, foto, lukisan, dan sebagainya"[14].

"Secara umum media merupakan kata jamak dari medium, yang berarti perantara atau pengantar. Istilah dari media yang digunakan dalam bidang pengajaran atau pendidikan sehingga istilahnya menjadi media pendidikan dan pembelajaran. Namun demikian, media bukan hanya berupa alat atau bahan saja, akan tetapi hal-hal lain yang memungkinkan siswa dapat memperoleh"pengetahuan. Gerlach dan Ely menyatakan: "A medium, conceived is any person, material or eventthat establishs condition which enable the learner to acquire knowledge, skill, and attitude"[15]. "Menurut Gerlach secara umum media itu meliputi orang, bahan, peralatan, atau kegiatan yang menciptakan kondisi yang memungkinkan siswa memperoleh pengetahuan, keterampilan, dan sikap."Pengertian ini mengartikan bahwa media bukan hanya alat perantara saja seperti televisi, radio, bahan cetakan, tetapi meliputi orang atau manusia sebagai sumber belajar atau juga berupa kegiatan semacam diskusi, seminar, karya wisata, dimulasi, dan lain sebagainya yang dikondisikan untuk menambah pengetahuan dan wawasan, mengubah sikap siswa, atau untuk menambah keterampilan. 
Alat yang dapat membantu proses belajar siswa dinamakan media pembelajaran."Pemahaman dalam implikasi media untuk proses ini harus mendapatkan pengalaman terlebih dahulu dala pembelajaran siswa. Edgar Dale mengambarkan hal tersebut dalam sebuah kerucut kemudian dinamakan kerucut pengalaman (cone of experience). Kerucut pengalaman ini pada saat ini dianut secara luas untuk menentukan alat bantu atau media apa yang sesuai agar siswa memperoleh pengalaman belajar secara mudah.

"Kerucut pengalaman yang dikemukakan [16] memberikan gambaran bahwa pengalaman belajar yang diperoleh siswa dapat melalui proses perbuatan atau mengalami sendiri apa yang dipelajari, proses mengamati dan mendengarkan melalui media tertentu dan proses mendengarkan melalui bahasa."Semakin konkret siswa mempelajari bahan pengajaran, maka semakin tinggi tingkat pemahamannya."Contohnya adalah melalui pengalaman secara langsung, maka semakin banyak pula pengalaman yang diperoleh oleh siswa dan sebaliknya semakin banyak abstrak siswa yang memperoleh pengalaman, contohnya dengan menggunakan bahasa yang verbal, maka akan semakin sedikit bagi siswa untuk memperoleh pengalaman."

"Melalui penelitian ini, media audiovisual bagi mahasiswa BIPA disusun sebagian rupa untuk mempermudah pengajar BIPA mengajarkan bahasa dan budaya Indonesia kepada penutur asing secara maksimal serta sesuai dengan kondisi yang nyata di lapangan. ”Menurut [16], materi ajar memiliki beberapa fungsi, yakni fungsi edukatif, fungsi sosial, fungsi ekonomi, fungsi politis, dan fungsi seni budaya. Penulis meyakini bahwa penutur asing akan semakin tertarik mendalami materi BIPA jika semua fungsi tersebut dimuat didalam sebuah materi ajar yang berkualitas. Implementasi fungsi yang mendukung nilai kearifan lokal bangsa Indonesia dapat terwujud jika materi BIPA mencantumkan berbagai elemen-elemen kearifan lokal seperti benda-benda budaya, gerak-gerik anggota badan, jarak fisik ketika berkomunikasi, penyentuhan, adat-istiadat yang berlaku di masyarakat, sistem nilai yang berlaku di masyarakat, sistem religi yang dianut masyarakat, mata pencaharian, kesenian, pemanfaatan waktu, cara berdiri/duduk/menghormati orang lain, keramahtamahan/tegur sapa/ basa basi, pujian, gotong royong, sopan santun [17] [18]. Penulis dalam penelitian mengembangkan sebuah materi berbasis multimedia yang termuat dalam bentuk"audiovisual yang diadaptasi dari Taksonomi Bretz yang menggabungkan budaya lokal dan audiovisual. "Media ajar ini menggunakan materi dalam bentuk ilustrasi audiovisual yang berisikan materi bahasa budaya lokal dan bahasa Indonesia yang dapat menarik minat penutur asing dan melatih kemampuan mendengar dan berbicara."

\section{SIMPULAN}

Secara umum, dalam sebuah pengajaran, khususnya pengajaran bagi mahasiswa BIPA seorang pengajar haruslah terampil dan kreatif dalam menyampaikan pembelajaran. mengingat bahwa mahasiswa BIPA selain belajar bahasa, sastra, sekaligus budaya Indonesia dituntut untuk mengetahui makna dari sebuah ujaran Bahasa Indonesia. Audiovisual sebagai bahan ajar bagi mahasiswa BIPA berisi mengenai gesture audio yang berisi aksen-aksen khas budaya bangsa Indonesia, dan lagu-lagu kebangsaa serta lagu-lagu daerah yang dapat diaplikasikan dalam pembelajaran BIPA. Secara umum, penelitian ini dapat disimpulkan bahwa materi pembelajaran Bahasa Indonesia bagi Penutur Asing (BIPA), pengajar hendaknya memberikan tujun pembelajaran yang jelas dan teliti serta harus mengembangkan materi pembelajaran yang dapat mengakomodasi siswa dan menarik minat pemelajar dengan gaya pembelajaran yang berbedabeda. 


\section{REFERENCES}

[1] J. N. Sneddon, "Directions in Indonesian-language teaching: formal, informal or both?," Asian Stud. Rev., 1990, doi: 10.1080/03147539008712685.

[2] I. M. P. Widiatmika, M., I Gede Mahendra Darmawiguna, "PENGEMBANGAN FILM SERI ANIMASI 3D 'CERITA MADE' SEBAGAI MEDIA PEMBELAJARAN BIPA DI UNIVERSITAS PENDIDIKAN GANESHA,” Kumpul. Artik. Mhs. Pendidik. Tek. Inform., 2019, doi: 10.23887/karmapati.v8i1.16982.

[3] R. Ellis, "Form-Focused Instruction and Second Language Learning," in Language Teaching Research and Language Pedagogy, 2012.

[4] A. Kusmiatun, "TOPIK PILIHAN MAHASISWA TIONGKOK DALAM PEMBELAJARAN BIPA PROGRAM TRANSFER KREDIT DI UNY," LITERA, 2016, doi: 10.21831/ltr.v15i1.9773.

[5] I. Suyitno, "Pengembangan Bahan Ajar Bahasa Indonesia untuk Penutur Asing (BIPA) berdasarkan Hasil Analisis Kebutuhan Belajar," Wacana, J. Humanit. Indones., 2007, doi: 10.17510/wjhi.v9i1.223.

[6] E. Dale, "The Learning Pyramid," Audio Vis. methods Teach., p. 43, 1954.

[7] R. Barnard, J. C. Richards, and T. S. Rodgers, "Approaches and Methods in Language Teaching," TESOL Q., 2002, doi: 10.2307/3588247.

[8] J. C. Richards and T. S. Rodgers, "The nature of approaches and methods in language teaching," in Approaches and Methods in Language Teaching, 2010.

[9] B. Kumaravadivelu, "TESOL Methods: Changing Tracks, Challenging Trends," TESOL Q., 2006, doi: 10.2307/40264511.

[10] W. Fujisaki, S. Shimojo, M. Kashino, and S. Nishida, "Recalibration of audiovisual simultaneity," Nat. Neurosci., 2004, doi: 10.1038/nn1268.

[11] A. J. Friedman, R. Cosby, S. Boyko, J. Hatton-Bauer, and G. Turnbull, "Effective teaching strategies and methods of delivery for patient education: A systematic review and practice guideline recommendations," in Journal of Cancer Education, 2011, doi: 10.1007/s13187-010-0183-x.

[12] H. Mudjia Rahardjo, "Triangulasi dalam Penelitian Kualitatif," Universitas Islam Negeri Maulana Malik Ibrahim Malang, 2010. .

[13] Sugiyono, "Memahami Penelitian Kualitatif," Bandung Alf., 2016.

[14] W. Sanjaya, "Strategi Pembelajaran Berorientasi Standar Proses Pendidikan," System, 2010.

[15] G. E. Evans, "Teaching and media: A systematic approach," Inf. Process. Manag., 1976, doi: 10.1016/0306-4573(76)90059-5.

[16] A. Azis, "Kompetensi Guru Dalam Penggunaan Media Dengan Mutu Pendidikan,” J. Pelopor Pendidik., 2014.

[17] Brata Ida Bagus, "Kearifan BudayaLokal Perekat Identitas Bangsa," J. Bakti Sar. Diakses Pada Hari Minggu 20 Juli 2019. Pukul 00.00 WIB, 2016, doi: 10.1007/s11104008-9614-4.

[18] K. Saddhono, A. Hasibuan, and M. I. Bakhtiar, "Facebook as A Learning Media in TISOL (Teaching Indonesian to Speakers of Other Languages) Learning to Support The Independency of Foreign Students in Indonesia," in Journal of Physics: Conference Series, 2019, vol. 1254, no. 1, p. 12061. 